\title{
PROBLEMAS ASSISTENCIAIS DE ENFERMAGEM NOS HOSPITAIS E CLÍNICAS PARTICULARES
}

\author{
Taka Oguisso * \\ Maria José Schmidt
}

\begin{abstract}
\begin{tabular}{l|c|}
\cline { 2 - 2 } & RREn/03 \\
\hline
\end{tabular}
OGUISSO, T. e SCHMmT, M.J. - Problemas Assistenciais de Enfermagem nos Hospitais e Clínicas Particulares. Rev. Bras. Enf.; DF, 28 : 24-37, 1976.
\end{abstract}

\section{INTRODUÇÃO}

O tema deste simpósio - problemas assistenciais de enfermagem - sempre constituiu objeto de preocupação das profissionais enfermeiras, haja vista a quantidade de trabalhos já publicados no órgão oficial de divulgação da classe.

Trabalhos com base em levantamentos, em análises de sistemas ou de instituiçōes e em relatos de experiências ou de situaçōes têm sido apresentados nos Congressos de Enfermagem como temas de pesquisa ou temas livres. Realmente, a tônica constante nas conclusōes desses trabalhos têm sido a constatação da deficiência qualitativa e quantitativa da assistência de enfermagem. Porém, dada a relevância e gravidade do assunto, em especial nos hospitais e clinicas particulares, quis a Comissão de Temas deste Congresso, que o mesmo voltasse à discussão com maior ênfase e destaque, para que nós, profissionais enfermeiras, pudéssemos refletir e dirigir a atenção no sentido de procurar e tentar, na medida das possibilidades, corrigir essas falhas.

A casuística em que se fundamenta este trabalho revela inúmeros problemas já velhos conhecidos e reconhecidos dentro de nossas insti tuiçōes e serviços de saúde. Entretanto, continuam eles a persistir, num verdadeiro desafio à nossa coragem e decisão para enfrentá-los.

A literatura contemporânea está vasada de expressōes e termos que tentam conceituar e dar novas dimensōes à enfermagem como assistência. Quaisquer que sejam ess,as expressōes, tomadas por empréstimo de outras profissōes ("diagnóstico de enfermagem", "prescrição de enfermagem", "evolução de enfermagem" e outras) o que vale é que continuamos, ou devemos continuar a entender que, a enfermagem hospitalar, como conceitua LAMBERTSEN (1966) é "uma assistência individual e contínua prestada ao paciente,

* Enfermeira da Subdiretoria de Planejamento do INPS em São Paulo e docente da Escola de Enfermagem da Universidade de São Paulo.

* Enfermeira da Subsecretaria de Seguros Sociais do INPS em São Paulo. 
OGUISSO, T. e SCHMDT, M.J. - Problemas Assistenciais de Enfermagem nos Hospitais e Olínicas Particulares. Rev. Bras Enf.; DF, 28 : 24-37, 1976.

a qual pode variar de acordo com a condição de saúde do mesmo, desde o estado de dependência total em relação à enfermeira, quando esta faz para ele tudo quanto ele não pode fazer por si, até que possa tomar conta de si mesmo, passando pelos estados intermediários em que a enfermeira presta apenas cuidados de proteção e reabilitação, tanto física quanto emocional". Ou ainda, podemos repetir com Ujhely, citado por CARVALHO (1972), que é específico na enfermagem o "auxílio e apoio ao paciente durante toda a sua experiência de indivíduo enfermo. Significa estar perto, amparar, oferecer compreensão, ouvir, acompanhar nas dificuldades, ensinar, encorajar, aliviar sofrimentos, suprir deficiências determinadas pela doença, oferecer apoio moral; respeitando sempre seus direitos de homem".

Embora o ideal seja, realmente, a prestação da assistência direta e pessoal ao paciente pela enfermeira, a não ser em Unidades de Terapia Intensiva e em alguns poucos hospitais governamentais que contam em seu quadro de pessoal com enfermeiras em número até razoável, a grande maioria ou a quase totalidade dos hospitais não governamentais não dispōe, ainda, de enfermeiras para dar cobertura assistencial direta. Mesmo entre aqueles hospitais não governamentais que contam com uma ou mais enfermeiras, estas, em geral, figuram apenas nos cargos diretivos do serviço de enfermagem do hospital ou em chefia de centro cirúrgico e/ou obstétrico ou em supervisão de grandes áreas, às vezes, extrapolando o próprio serviço de enfermagem e responsabilizando-se por setores outros como nutrição e lavanderia.

Esta é, portanto, uma das primeiras características de hospital não governamental, isto é, a carência permanente de profissional enfermeira. Esse problema é considerado por muitas enfermeiras como insolúvel, pois a primeira preo- cupação de qualquer empresário, assim considerado também os proprietários ou sócios e o diretor do hospital, é obter o máximo de renda ou receita com o minimo da despesas. $O$ aumento da receita é, em geral, obtido mediante economia na contratação de pessoal qualificado. Por ser mais onerosa a contratação de enfermeiras, estas são substituídas por auxiliares de enfermagem e até por atendentes, a quem são entregues atribuiçōes e responsabilidades que deveriam caber somente às enfermeiras.

As entidades não governamentais de assistência à saúde caracterizam-se também pelo seu aspecto essencialmente curativo, ou seja de prevenção secundária ou de recuperação. Poucas são as que oferecem serviços de controle de saúde, e mesmo as clínicas que os oferecem, não o fazem de forma exclusiva; pois, quando é detectada uma moléstia, esta é acompanhada e tratada. Se assim não fosse, não sobreviveriam estas entidades, pois ainda não existe, mesmo entre os profissionais da saúde, uma efetiva mentalidade de controle preventivo das doenças.

Neste trabalho foram considerados "hospitais e clínicas particulares" todas as entidades não governamentais de assistência à saúde, seja em caráter de emergência, ambulatorial ou hospitalar. Muitas vezes, estas entidades utilizam expressōes ou termos para sua denominação, que, analisadas cientificamente, não traduzem exatamente a sua finalldade. Tal é o termo "clínica", largamente utilizado para designar entidades ou equipes médicas dedicadas à medicina de grupo em consultórios conjuntos. O Dicionário Médico de Pacheco Fortes diz que "clínica é a prática ou exercício da medicina; a arte de estudar as doenças e seus sintomas mediante a observação direta do doente. Estabelecimentos em que pacientes consultam médicos para serem internados". O Dicionário Terminológico de Ciências Médicas da 
OGUISSO, T. e SCFMIDT, M.J. - Problemas Assistenciais de Enfermagem nos Hospitais e Clínicas Particulares. Rev. Bras. Enf.; DF, 28 : 24-37, 1976.

Salvat Editores dispõe que "clínica é instituição médica oficial ou particular, em que se ensina a prática da medicina ao lado da cama dos doentes. Por extensão, dá-se o nome de clínica a qualquer instituição em que se tratam doentes, especialmente acamados".

O serviço ou unidade de emergência "é a unidade hospitalar que se destina a receber pessoas necessitadas de socorro imediato". As expressões "unidade de emergência" e "pronto socorro" parecem sugerir a idéia de gravidade, de algo quase próximo à morte; contudo, embora esses estabelecimentos visem especialmente os casos que inspiram maiores cuidados, destinam-se a atender também ocorrências menores, que não revestem especial gravidade" (11).

Os problemas levantados neste trabalho constituem fruto da observação pessoal por ocasião das 128 visitas de verificação a entidades particulares, entre as quais 102 hospitais, clínicas e prontos socorros particulares que receberam também visita de orientação, vistoria ou revistoria. Além destas visitas foram incluidas também as observações realizadas no decorrer do trabalho de investigação para coleta de dados para tese de uma das autoras. Visita de verificação é a feita com o objetivo de observar sumariamente a existência ou não de condições minimas que satisfaçam as exigências de instalação, equipamentos e funcionamento para assistência aos acidentados do trabalho. A vistoria ou revistoria tem caráter mais formal e busca apenas fazer uma avaliação objetiva da situação encontrada pela equipe.

Estas visitas de verificação, orientação, vistoria ou revistoria foram realizadas por equipe multiprofissional do INPS de São Paulo, constituída de um ou dois médicos, uma enfermeira e um ou mais funcionários administrativos, no periodo de abril de 1972 a dezembro de 1974 . Tais visitas, vistorias e revistorias feitas a entidades particulares, todas locali- zadas na área da Grande São Paulo, tínham por objetivo a avaliação das condições para fins de credenciamento, atualização de credenciamento ou orientação quanto ao atendimento de acidentados do trabalho.

Para facilitar a abordagem dos problemas assistenciais de enfermagem, estes foram classificados em: técnicoprofissionais, administrativos, educacionais e éticos. Além da análise descritiva do problema fez-se um relato sumário de fatos e situações observadas pessoalmente nas visitas e vistorias a entidades particulares anteriormente mencionadas.

\section{I - PROBLEMAS TECNICO- PROFISSIONAIS}

1. Esterilização do material - é o aspecto, entre todos, o mais descuidado.

Foram incluídos neste item não só o material permanente, isto é, instrumental para curativos e pequena cirurgia, como material de consumo constituído por seringas, agulhas, sondas, drenos, luvas e outros. Raros são os hospitais que dispõem de instrumental em quantidade razoável, e quando dispōem, esse material é de uso exclusivo dos médicos no centro cirúrgico. Assim, o pessoal de enfermagem, tanto nas unidades de internação como nos ambulatórios, não tem acesso a esse material. A carência de material já de per si dificulta a esterilização, especialmente, se o hospital não conta com autoclave de esterilização rápida. Fato freqüente é a substituição, por algumas enfermeiras, da esterilização a vapor sob pressão pela química, não se preocupando, entretanto, pelo tempo de imersão do material, concentração e durabilidade da solução, condições de conservação e outros fatores. Poder-se-ia dizer que algumas enfermeiras chegam a atribuir a tais soluções químicas um poder quase milagroso de esterilização, tal a confiança com que permitem a livre manipulação de ins- 
OGUISSO, T. e SCFMIDT, M.J. - Problemas Assistenciais de Enfermagem nos Hospitais e Clínicas Particulares. Rev. Bras. Enf.; DF, 28 : 24-37, 197.

trumental colocado nestas soluções por apenas alguns minutos. Observadas a respeito, alegam "não ter havido nenhum caso comprovado de contaminação decorrente de material assim esterilizado". Outras há que comentam que a vida profissional prática é totalmente diferente do que se ensina na escola, onde tudo é mostrado numa situação irreal, à base do ideal. E assim, passam a encarar tudo o que a escola ensinou em termos de assepsia, microbiologia, química e outras ciências apenas como conhecimento teórico de aplicabilidade restrita ao ambiente acadêmico. Entretanto, aí estão as teses e pesquisas sobre infecção hospitalar, que provam e comprovam sobejamente a sua existência. Uma jornalista americana, Joan Arehart Treichel, redatora da "Enterprise Science News", uma agência internacional de notícias científicas, analisando um relatório de pesquisa, concluiu que "embora sejam impressionantes os índices de infecções hospitalares, são mais assustadores os modos de sua transmissão" (9) .

A título de ilustração, descreveremos algumas situações encontradas:

1.1. Pinças para tricotomia - colocadas em vidros com solução de "Germikil" em concentração desconhecida pelos próprios usuários e em quantidade tão insuficiente no frasco, que apenas dois ou três centímetros da extremidade da pinça ficam imersos. Esta única pinça é usada em todas as pacientes, situação particularmente grave, considerando que as entidades observadas eram maternidades de grande movimento. Em idêntica situação foi encontrado o perfurador de bolsa.

1.2. Pinças de curativo - em diversos hospitais e clínicas, inclusive com atendlmento de queimados e de cirurgia plastica, foram encontradas algumas poucas pinças de Kocher, Pean ou Anatômica sendo "esterilizadas" por alguns segundos em solução química. Fato observado numa clínica de atendimento de acidentados, em regime ambulatorial, foi o de uma só funcionária de enfermagem fazer dois ou três curativos de pacientes diferentes ao mesmo tempo com uma só pinça, cuja extremidade era imersa apenas para descanso na solução contida no fundo de um vidro. Estes pacientes ficavam sentados ao redor de uma mesa, e expunham a área do ferimento para ser feito o curativo. Outro fato constatado fol o uso de um só pacote de curativo para dois pacientes internados num mesmo quarto. 0 executante realizou primeiro o curativo de fístula de osteomielite e, em seguida, o de cirurgia torácica, do paciente em leito vizinho, no mesmo quarto.

1.3. Seringas - constitui ainda problema muito comum principalmente sob três aspectos: deficiência quantitativa, má utilização e precariedade de esterilização. A insuficiência de seringas e agulhas gera automaticamente a deficiência na esterilização e a inobservância de princípios técnicos.

Mesmo em hospitais com sofisticados equipamentos eletrônicos servindo de motivo de ostentação e orgulho, foi encontrada esterilização de seringas e agulhas nas unidades de internação e ambulatório feita em esterilizadores elétricos a ebulição e até em panelas de alumínio, do tipo doméstico.

Se, pelo menos, fossem observados os princípios mínimos para assegurar a esterilização do material, seria tolerável a utilização desses esterilizadores elétricos. Tais princípios seriam: troca de água, pelo menos diariamente, após lavagem rigorosa do esterilizador, observação do tempo de ebulição para seringas e agulhas, separação do material de borracha dos ferros, manutenção do nível de água em quantidade suficiente que permitisse a imersão de todo o material a ser esterilizado. Na prática, o que se observa é - que foi relatado por ENGEL (1964): "Cansamos de observar material para 
OGUISSO, T. e SCHMIDT, M.J. - Problemas Assistenciais de Enfermagem nos Hospitais e Clinices Particulares. Rev. Bras. Enf.; DF, $28: 24-37,1976$.

aplicação de injeçōes ou curativos, ser retirado do esterilizador no momento em que a água apenas entra em ebulição ou, em que, um instrumento contaminado é colocado. O esterilizador passa. às vezes, um mês inteiro sem ao menos se trocar a água; as agulhas geralmente são rombudas, tortas e o material é colocado para esterilizar sem antes ser lavado, misturando-se pinças, sondas e seringas".

O número insuficiente de seringas leva o funcionário a utilizar a mesma seringa para ministrar dieta de sonda e injeções endovenosas, entremeadas por uma rápida "esterilização" pela fervura.

Outra decorrência do número insuficiente de seringas, é que o funcionário aplica várias injeções, às vezes, até de substâncias diferentes com a mesma seringa, trocando apenas a agulha. Quando observados a esse respeito, Justificam a medida, alegando não haver perigo de contaminação, porque não aspiram após a introdução da agulha no músculo.

1.4. Roupas de utilização em salas cirúrgicas - campos, aventais, compressas e outros materiais de fibras vegetals necessitam ser esterilizados em autoclave. Entretanto, fol observado proceder-se a esterilização desse material em calor seco ou estufa, e isto para cirurgia geral, neurocirurgia e cirurgia plástica. A enfermeira argumentou que adotara este procedimento porque a única autoclave existente na entidade era do tipo de laboratório, que não dava secagem, e só era utilizado para instrumental.

1.5. Mamadeiras de hidratação em berçário - além de serem individuais para cada recém-nascido, estes recipientes deveriam ser lavados e depois esterilizados em autoclave, uma vez por dia. Contudo, verificou-se, em alguns berçários, a utilização de uma única mamadelra de chá para hidrataçáo coletiva, Isto é, para cerca de 20 a 25 crianças.
2. Banho de imersão em crianças o banho de lactentes é dado, via de regra, por imersão em bacia ou em banhelras especiais. O ideal seria a instalação de banheiras infantis em aço inoxidável, tendo em continuação um tampo do mesmo material, de fórmica ou de mármore para facilitar a troca de roupa da criança. Recomenda-se ainda a instalação de chuveirinho com água quente, e a utilização de plástico fino para revestir internamente a banheira. Após cada banho, o plástico é perfurado para eliminação da água usada, sendo conseqüentemente inutilizado e jogado fora. Assegura-se, assim, a higiene adequada da criança sem o risco de contaminações cruzadas. A realidade que se nos apresentou foi a utilização da mesma água, na mesma banheira, para o banho de diversas crianças, trocando-se apenas a toalha.

3. Promoção de ambiente terapêutico - função típica da enfermeira é proporcionar facilidades e condições de apoio para o trabalho da equipe de saúde, assim como, o bem-estar do paciente. Deve ainda analisar o fluxograma das áreas de atendimento, em especial, dos serviços de emergência e ambulatório e, procurar dotá-los de algumas condiçōes quase sempre esquecidas pela direção de entidades particulares. Um desses aspectos é a destinação de uma área para repouso pré e pós pequenas cirurgias de ambulatório, para secagem de aparelho gessado, para observação em casos de mal súbito, para tratamento de emergência de pacientes graves enquanto aguardam internação ou remoção. Também, quando o hospital não possui uma unidade de terapia intensiva (UTI), ou de recuperação pós-anestésica, compete à enfermeira procurar reunir, principalmente os casos de grandes cirurgias, em um local apropriado para assegurar maior observação e controle desses operados. Foram encontradas situações em que a falta de área para repouso de pa- 
OGUISSO, T. e SCHMIDT. M.J. - Problemas Assistenciais de Enfermagem nos Hospitais e Clínicas Particulares. Rev. Bras. Enf.; DF, 28 : 24-37, 1976.

cientes, em especial, nas unidades de emergência e ambulatório, determinava a localização dos mesmos em maca nos corredores, sem proteção e vigilância alguma, servindo de espetáculo à curiosidade pública, muitas vezes sem roupa, apenas cobertos por um lençol, mesmo em dias e noites frias. Além dos casos que sofreram agravamento por pneumonia, vários casos outros sofreram quedas dessas macas, com graves implicaçōes policiais e judiciais, conforme está relatado na tese "Os aspectos legais da anotação de enfermagem no prontuário do paciente". A dispensa de pacientes imediatamente após a confeç̧ão do aparelho gessado, sem um minimo ce ropouso, acarreta deformaçōes no gesso. Estas, por sua vez, se não forem refeitas, ocasionam sequelas, por vezes, irreparáveis.

Outra situação bastante constrangedora foi constatada em um hospital com pronto socorro, onde quatro ou cinco pacientes recebiam hidratação endoverosa, sentados em cadeiras comuns, ao redor de cada suporte de soro.

Há ainda, entidades que destinam uma sala para curativos ambulatoriais, porém localizada no subsolo, sem janelas, impossibilitando, portanto, a ventilação e iluminação naturais. Estas mesmas salas serviam concomitantemente de consultório médico, e ambos, médico e atendente de enfermagem, trabalhavam juntos, um dando consulta e a outra fazendo o curativo de um ou mais pacientes, ao mesmo tempo.

4. Administração de medicamentos - constitui uma das unidades de ensino das escoias de formação de pessoal de enfermagem e é considerada uma das atividades mais importantes, tanto pela responsabilidade de que é investida a tarefa, como pela influência direta que exerce na recuperação do paciente. A atividade completa de administração de medicamentos inclui desde a observação da prescrição médica, o preparo, a ad- ministração propriamerte dita e a anotação respectiva.

Apesar da importância e responsabilidade que envolve esta atividade, há enfermeiras que, mesmo em caso de dúvida ou até de engano, por parte do médico com relação ao paciente ou ao medicamento, determinam que o mesmo seja ministrado. Justificam esta atitude alegando que "se está prescrito a responsabilidade é do médico", esquecendo-se de que como profissional ela também assume a sua parcela de responsabilidade. Por outro lado, quando se enganam administrando medicação trocada, afirmam enfaticamente que tais erros "são pequenas falhas sem maiores conseqüências". Quando a troca é de paciente, em geral, o pessoal de enfermagem ao descobrir a falha, apenas administra o medicamento para o paciente certo. Aquele que recebeu indevidamente nem chega a tomar conhecimento, pois segundo depoimento de uma enfermeira tudo é foito para que o doente não descubra, pois se descobrir pode vir a perder a confiança no hospital.

Foi observada a administração de artibiótico (Binotal) por via oral, prescrito para ser dado de 6/6 horas, e ser ministrado de uma só vez a dose total das 24 horas.

Anotar, "checando" a medicação antes de aplicar é outra sistemática comum adotada por alguns profissionais de enfermagem nos hospitais. Conseqüentemente, muitos medicamentos não chegam a ser administrados, mas estão "checados" previamente. Auxiliares de enfermagem em dois hospitais informaram terem recebido ordens superiores para "checar" toda medicação prescrita.

Uma enfermeira, chefe do serviço de Enfermagem de um hospital, informou que, em virtude de inúmeros desentendimentos havidos com médicos, adotara a sistemática de só anotar a medicação prescrita, os dados do pulso e da pressão 
OGUISSO, T. e SCHMDDT, M.J. - Problemas Assistenciais de Enfermagem nos Hospitais e Clínicas Particulares. Rev. Bras. Enf.; DF, $28: 24-37,1976$.

arterial. Relatou que esses desentendimentos eram decorrentes de anotações do pessoal de enfermagem sobre reações observadas, queixas de dores ou outros sintomas subjetivos dos pacientes. Em seguida a essas anotações, o pessoal fazia constar também a comunicação feita ao próprio médico do paciente ou ao plantonista. Entretanto, por sobrecarga de outros setores do hospital (Pronto Socorro), principalmente à noite, tais chamados, freqüentemente, não eram atendidos. Em outro dia, o médico ao passar visita e verificando tal anotação, simplesmente inutilizava a folha de "Prescrição Médica e Relatório de Enfermagem", não se incomodando até em transcrever a prescrição anterior, mas exigindo que o pessoal de enfermagem também refizesse as anotações, retirando aquelas que pudessem determinar glosa da conta hospitalar por parte da instituição conveniente.

Problema dos mais comuns, observado até em hospitais considerados de elevado padrão, é o da substituição de medicamentos mais caros por outros mais baratos. $O$ pessoal de enfermagem prepara medicamentos, inclusive de amostras grátis, e aplica nos pacientes, de quem são cobrados os preços usuais de farmácia. Tal fato foi inclusive denunciado por estudantes de medicina de oito centros acadêmicos, que em recente declaração oficial a um jornal de grande circulação em São Paulo, admitiram o baixo padrão ético e técnico de hospitais e clínicas particulares. Estes estudantes afirmaram que "no caso da venda de amostras grátis, o cliente fica normalmente sem condições de descobrir a fraude, já que o remédio é aplicado ao doente sob forma de comprimidos ou de liquidos fora de sua embalagem e, por isso, sem a indicação da oferta gratuita dos fabricantes..." (8)

Entretanto, esses estudantes consideraram como fraude mais freqüente, a aplicação de um medicamento mais ba- rato, que é cobrado do cliente pelo preço de outro mais caro. Como exemplo citaram a substituição da Garamicina pela Quemicetina, ambos antibióticos. O preço de farmácia da Garamicina, em abril de 1975 , era de $\mathrm{Cr} \$ 24,00$ por oitenta miligramas, e o da Quemicetina era de Cr\$ 9,07 por mil miligramas (8).

5. Aplicação de tratamentos - A execução do tratamento prescrito pelo médico é, em geral, de competência do pessoal de enfermagem. Para isso, os profissionais devem receber formação técnica ou treinamento. Foram observados, todavia, alguns casos, cujo relato será suficiente para alcançar a sua gravidade.

5.1. Sondagem gástrica ectópica tratava-se de um paciente com acidente vascular cerebral, para quem o médico prescrevera alimentação por sonda gástrica. Esta foi passada por um auxiliar de enfermagem. A sonda ficou localizada na árvore brônquica, onde foi introduzida também a dieta. Constatado o erro, foi feita aspiração e recolocação da sonda, mas o paciente faleceu no dia seguinte. O laudo da necropsia revelava morte por pneumonia aspirativa.

5.2. Curativos - um paciente de 72 anos de idade, portador de tromboangeíte obliterante, foi internado no hospital para amputação do $2 .^{\circ}$ artelho do pé direito, que se encontrava necrosado. Ele apresentava também eczema nas extremidades dos membros inferiores. A enfermeira fazia pessoalmente os curativos com uma solução de Fenosalil, na proporção de uma colher das de sopa de soluto para um litro de água, conforme prescrição médica. Na véspera de suas folgas acumuladas de cinco dias, orientou um auxiliar de enfermagem para continuar os mesmos curativos. Entretanto, segundo a própria enfermeira, esqueceu-se de avisar a composição exata da solução .O auxiliar aplicou o soluto puro sobre a área das lesões eczematosas durante os cinco dias em que 
OGUISSO, T. e SCHMIDT, M.J. - Problemas Assistenciais de Enfermagem nos Hospitais e Clínicas Particulares. Rev. Bras. Enf.; DF, $28: 24-37,1976$.

a enfermeira ficou ausente. Desse incidente, o paciente que fora admitido no hospital para um período provável de 5 a 7 dias, teve que permanecer internado por mais dois meses para tratamento das queimaduras provocadas pela substância. Neste caso, o período suplementar de internação ficou por conta do hospital, que assim assumiu a responsabilidade pelo evento danoso. Entretanto, no prontuário nenhuma anotação, seja do médico ou da enfermeira. revelava 0 acontecido. Apenas constavam curativos com -Furacin.

Outro caso, revelado também por enfermeira de hospital particular, foi o de queimadura nas regiōes inguinal e genital por água fervente em paciente do sexo masculino. A água colocada na bolsa de borracha fora aplicada por um atendente na região púbica, por estar o paciente com retenção urinária. A tampa, provavelmente não rosqueada o suficiente, escapou, fazendo com que a água fervente entornasse e provocasse queimaduras de 2.0 grau nas regiōes mencionadas. A enfermeira comentou que, desde essa época, todas as bolsas de água quente foram recolhidas para o almoxarifado, razão porque não houve repetição do caso.

5.3. Execução de tratamentos de alçada médica por funcionários da enfermagem - são os casos de confecção de aparelhos gessados, drenagem de abcessos, suturas, retiradas de corpo estranho de cavidades naturais, dilatações retais, uretrais, aplicação de transfusão de sangue e até pequenas cirurgias.

Para estes funcionários, geralmente práticos de enfermagem, é motivo de vaidade e até de 'status" dizer que executam esta ou aquela atividade, pois são chamados de "doutor" pelos pacientes. Os médicos, por indulgência, comodismo ou falta de responsabilidade continuam não só a facilitar, mas a exigir a presença destes funcionários, especialmente em ambulatórios. Freqüentemen- te, estes médicos interferem no serviço de enfermagem, impedindo que a enfermeira faça qualquer remanejamento desses funcionários, que lhe são subordinados.

\section{II - PROBLEMAS ADMINISTRATIVOS}

Aparentemente não sugere ser problema de relevância. Entretanto, as repercussões advindas desta atividade de enfermagem extrapoiam os limites do próprio serviço, atingindo setores outros como contabilidade, tesouraria e até o nome do próprio hospital.

Atualmente, são muitas as atividades burocrático-administrativas da enfermagem, não só relacionadas com previsão e requisição de material, equipamentos, aparelhos e medicamentos para a Unidade, como também relacionadas com a elaboração das próprias contas hospitalares dos pacientes.

Fato observado até com freqüência em alguns hospitais é a realização de cirurgias por um médico, e ser registrado o nome de outro na ficha de anestesia pelo anestesista e na anotação de sala, pela circulante. Em geral, o nome deste médico que fica registrado é o de algum professor de medicina, com certa fama e prestígio, justificando dessa forma, a cobrança de cirurgia de acordo com tabela de professor. O cirurgião, muitas vezes, quintanista ou sextanista de medicina, que efetivamente realizou a cirurgia, figura nas anotações e na conta hospitalar como assistente. O paciente embora operado por um médico (que não o dele) ou o estudante de medicina e uma intrumentadora, acredita ter sido operado por um "professor" de sua confiança absoluta. Assim, paga satisfeito a conta apresentada julgando ter sido atendido por uma equipe altamente especializada.

Aliás, este problema está se tornando cada vez mais grave. Com o aumento do número de escolas de medicina sem contar com campo apropriado para es- 
OGUIsso, T. e SCHMmT, M.J. - Problemas Assistenciais de Enfermagem nos Hospitais e Clínicas Particulares. Rev. Bras. Enf.; DF, $28: 24-37,1976$.

tágio e, principalmente, sem contar com professores em quantidade suficiente para acompanhar, orientar e supervisionar, os estudantes estão invadindo hospitais e clínicas particuiares munidios apenas da "coragem" que só mesmo a ignorância do risco e do perigo pode dar. Freqüentemente, o doente é examinado e socorrido por estudantes de medicina de $3 .^{\circ}$ ou $4 .^{\circ}$ ano, e até do $2 .^{\circ}$ ano, sem a assistência de médico responsável. Este, algumas vezes encontra-se em plantão à distância. E, o pessoal de enfermagem fica, principalmente à noite, sujeito a cumprir ordens e prescrições de pessoas não habilitadas, a preparar pacientes para laparotomia, sem antes ter se recorrido a outros meios clínicos para elucidação do diagnóstico. Ouvimos a cvfixa de um atendente, estudante de 2. ${ }^{\circ}$ ano de curso de auxiliar de enfermagem, demissionário de um hospital, onde trabalhava no Pronto Socorro, por "não agüentar mais assistir pacientes que entravam andando e morriam logo após a operação feita por estes estudantes de medicina".

Ainda com relação à prescrição médica em "papeleta única", onde são feitas de um lado a evolução e prescrição médica e de outro, o "relatório de enfermagem", foi encontrada a pitoresca prescrição médica, de "Repetir". Por sua vez, a enfermagem anotava, diariamente, "Repetido". Assim, sucessivamente por folhas e folhas a mesma prescrição e a mesma anotação de enfermagem.

A deficiência quantitativa e qualitativa das anotações de enfermagem é flagrante nos prontuários dos pacientes. Embora constitua determinação legal (Decreto 50.387/61), raros são os profissionais de enfermagem que a cumprem nos termos da lei e de forma conscienciosa.

Refazer uma folha de "relatório de enfermagem" atendendo pedido de médico para fazer constar apenas os dados mais convenientes, "passar a limpo" as anotações de enfermagem, filtrando também algumas anotações por iniciativa do próprio pessoal de enfermagem, como foi verificado em um hospital, deixar e anotar a substituição de um medicamento por outro, qualquer que seja a razão, ou não registrar ocorrências de acidentes com pacientes ou outros eventos que os tenham prejudicado são fatos em que o pessoal de enfermagem, principalmente a enfermeira, é diretamente responsável. Por receber maior formação e preparo, à enfermeira deveria caber a maior parcela de anotações sobre as observações realizadas a respeito do paciente. A delegação dessa competência aos demais membros da equipe de enfermagem deveria obedecer a determinados critérios; mesmo assim, a função deveria ser exercida sempre sob orientação e supervisão atenta e permanente da enfermeira. De qualquer forma, ela é responsável, em última análise, pelas anotações existentes ou inexistentes no prontuário.

O gráfico de TPR também é objeto de inúmeras ocasiōes para anotações "fantasmas". Parece ser freqüente 0 registro de TPR sem a devida verificação dos sinais vitais. Um dos motivos determinantes desse comportamento é o hospital não fornecer o instrumento necessário para a execução desta técnica. Há vários hospitais em que o termômetro é de propriedade do funcionário. Este, ao quebrá-lo não tem, de pronto, possibilidade para substituí-lo.

Em um prontuário foi constatada a anotação de "Paciente rebelde", feita pelo pessoal de enfermagem. Soubemos, posteriormente, que tal anotação fora devido ao paciente ter recusado um medicamento. Não se preocupou o funcionário em verificar os verdadeiros motivos e nem em anotar objetivamente a informação.

\section{III - PROBLEMAS EDUCACIONAIS}

Neste Item foram incluidos os aspectos 
OGUISSO, T. e SCHMWDT, M.J. - Problemas Assistenciais de Enfermagem nos Hospitais e Clínicas Particulares. Rev. Bras. Enf.; DF, 28 : 24-37, 1976.

de educação em serviço, supervisão do pessoal e orientação de pacientes e familiares. Quase todos os problemas até aqui levantados poderiam ser solucionados com um programa de treinamento sistemático do pessoal de enfermagem e supervisão permanente desse pessoal.

O probiema mais grave e comum encontrado, que foi o relacionado com a esterilização de material, é uma questão que pode ser, em grande parte, sanada pela supervisão após um periodo de treinamento. Isto, entretanto, partindo da premissa de que a enfermeira está absolutamente consciente da importância e necessidade da esterilização e sabe executar com perfeição, pelo menos, todas as técnicas básicas da enfermagem. Tal fato, contudo, embora lamentável, é mister que se diga, pois algumas enfermeiras, quando entrevistadas, após vistoria, confessavam simplesmente não ter segurança para executar esta ou aquela técnica. Entre estas técnicas destacamos a sondagem gástrica, vesical, enteroclisma, certos curativos e até aplicação de venoclise. Conseqüência direta desta insegurança será, por certo, a fuga destas situações, em detrimento da supervisão e orientação de funcionários, função especifica de competência das enfermeiras nesses hospitais.

Uma das queixas mais comuns em hospitais particulares é quanto às visitas e acompanhantes, que segundo algumas enfermeiras "só atrapalham o serviço".

A realidade é que o nosso povo, de um modo geral, ainda não sabe visitar docnte. Ou as visitas são excessivamente longas, cansando o paciente com conversas paralelas e até inconvenientes, ou os visitantes levam alimentos muitas vezes contra-indicados para o tipo de regime dietético prescrito. Visitas curtas e sucessivas de diversos visitantes também impossibilitam o repouso, geralmente indicado para quase todas as situações em que tenha havido necessidade de internação.

As escolas de formação, tanto de enfermeiras, como de auxiliares de enfermagem e atualmente dos técincos em enfermagem, utilizam como campo de estágio hospitais governamentais. Estes contam com uma clientela constituída mais por pessoas de escolaridade e condições sócio-econômicas limitadas, sem acompanhantes, e com horário de visitas restrito a uma ou duas vezes por semana, num total de 2 ou 4 horas semanais.

FELDMAN, M. A. et al (1973) observaram que talvez a falta dessa experiência no estágio enquanto estudantes. explique a insegurança e a fuga, especialmente das enfermeiras, do relacionamento com os familiares dos pacientes.

Tendência que se nota, em especial, nos hospitais governamentais e também em determinadas unidades de hospitais particulares é restringirem, ao máximo, as visitas e acompanhantes.

O hospital, pela sua própria natureza, condiciona nos pacientes a sensação de insegurança, além de acarretar temores e angústias que podem ser minoradas pela presença e atuação de um acompanhante bem orientado pela enfermagem. Além deste importante aspecto psicológico e humano que contribui para o mais rápido restabelecimento do doente, o acompanhante pode, ainda, prestar grande colaboração à enfermagem, na vigilância do paciente e auxiliando na higienização e alimentação do mesmo.

\section{IV - PROBLEMAS ETICOS}

De todos, talvez seja o aspecto mais descurado pelas enfermeiras e por todo o pessoal de enfermagem. A ética é muito mais vivência do que conhecimento filosófico. Além de haver uma disciplina com esse nome, com carga horária, crédito e docente responsável, mais importante é que cada professora das 
OGUIsso, T. e SCFnMT T, M.J. - Problemas Assistenciais de Enfermagem nos Hospitais e Clínicas Particulares. Rev. Bras Enf.; DF, 28 :24-37, 1976.

disciplinas profissionais de enfermagem acredite e realize os preceitos éticos no decorrer de sua atuação profissional, no estágio ou fora dele. Só assim poderá ela integrar realmente estes aspectos na disciplina que leciona.

Um problema de extrema gravidade, que já fol constatado por outras colegas e continua a persistir, é a existência de enfermeiras que emprestam ou dão o nome para hospitais, sem neles prestarem qualquer serviço. GODOY \& SOUZA (1971) já disseram que uma determinada "norma do INPS, só celebrando convênios com entidades hospitalares que possuam enfermeiro na chefia do serviço de enfermagem é o primeiro passo para o progresso da profissão. lamentável que muitas colegas não compreendam ainda suas responsabilidades como profissionais e dêem apenas seu nome a algumas dessas entidades, em troca de uma gratificação ínfima sem maior atenção ao trabalho que lhes competiria executar nessas Unidades".

Seja qual for a gratificação oferecida pelo hospital, é fato que não pode ser tolerado por enfermeira alguma que se preze. Felizmente, aí está o Conselho de Enfermagem que tomará as medidas cabíveis para evitar abusos dessa natureza que só irão denegrir a imagem da verdadeira profissional perante o público.

Outro aspecto de indiscutível gravidade, e, ao mesmo tempo descuidado pelo pessoal de enfermagem é o sigilo profissional. Comentários feitos, levianamente, em corredores, elevadores, portarias, junto ao leito de outros pacientes ou na sala de cirurgia com o doente semi-anestesiado, são fatos encontrados e constatados a todo instante nos hospitais.

Somente a conscientização desse aspecto ético e a atitude da enfermeira atenta e zelosa poderão atenuar o problema do desrespeito ao sigilo e infundir na equipe de enfermagem, e quiçá, na de saúde o mais profundo respeito pelo paciente.

Há casos, porém, em que o pessoal de enfermagem respeita o sigilo. o caso do paciente que pergunta ao funcionário o nome do medicamento que lhe está sendo ministrado, a dosagem, ou os valores da pressão arterial, da temperatura ou outro dado qualquer. $\mathbf{E}$ o funcionário, para não "faltar ao sigilo profissional", responde com evasivas ou informa-o com termos subjetivos tais como, "a pressão está boa" ou "sua temperatura está normal", embora tenha constatado hipertensão ou febre. Se isto é válido para determmados pacientes, não o é para outros mais esclarecidos ou que tenham condiçōes e o direito de saber a verdade. Muitos são os profissionais da enfermagem que, indiscriminadamente, continuam a adotar esta atitude diante dos pacientes.

Fol-nos relatado o caso de uma auxiliar de enfermagem, grávida de quatro meses, que fora admitida como paciente no mesmo hospital onde trabalhava, com pequena homorragia. $O$ médico plantonista diagnosticou simplesmente "abortamento" e prescreveu solução glicosada com Orastina. Embora protestasse dizendo que queria o filho, que não queria abortar, mas sim, fazer o tratamento para evitar o abortamento, as colegas, auxiliares de enfermagem, dizendo "doente não sabe nada! nós é que sabemos o que é melhor para você". Ministraram o soro endovenoso e a paciente eliminou feto vivo.

Há ainda um problema, cuja solução dependerá da formação moral que a enfermeira tiver recebido. $O$ problema que está a nos desafiar é o das cirurgias llícitas ou feitas sem o consentimento da paciente.

Algumas enfermeiras levantaram esse problema, dizendo-se impotentes para resolvê-lo, pois os hospitais particulares continuam a fazer tais intervençōes, com ou sem o protesto delas. Afirma- 
OGUIsso, T. e SCHMIDT, M.J. - Problemas Assistenciais de Enfermagem nos Hospitais e Clínicas Particulares. Rev. Bras. Enf.; DF, 28 : 24-37, 1976.

ram que nesses hospitais, em geral, a remuneração é melhor, e se elas pedirem demissão por causa disso, no dia seguinte o cargo estaria preenchido por outra enfermeira e o problema são seria resolvido. Entretanto, muitas enfermeiras nem chegam a mencionar o caso como problema. Indagadas a respeito, afirmam simplesmente que cirurgias tais como laqueadura de trompas, curetagem uterina de abortamento evitável, microcesárea, vasectomia, etc., são feitas rotineiramente, no Centro Cirúrgico onde trabalham. Considerando-as intervençōes corriqueiras, de responsabilidade exclusiva do médico que realizou e da paciente que a solicitou.

Outro problema de solução difícil para a enfermeira é quando a paciente não concorda com determinado tipo de cirurgia. Não obstante, o cirurgiāo realiza a intervenção. Tal é o caso, por exemplo, de uma cesárea, em que o cirurgião aproveita para laquear a trompa sem ter havido consentimento da paciente, ou até contra a sua vontade, num flagrante desrespeito ao inalienável direito de liberdade de recusar tratamento extraorainário. Conhecedora do caso, caberia à enfermeira enfrentar a situação na defesa do interesse e do direito da paciente.

Considerado normal, mesmo pelas enfermeiras e, portanto, não mais visto como problema é o caso das propinas. Muitas consideram não haver nada de errado, e até, pelo contrário, acham "bom que os funcionários que ganham pouco sejam beneficiados".

Ninguém ignora que nos hospitais particulares os pacientes procuram ser melhor assistidos prometendo ou oferecendo gratificaçōes extras. A realidade é que, de fato, os funcionários passam a dosar a sua boa-vontade e rapidez no atendimento na medida da propina recebida, aviltando o que há de humanitário na arte de servir, "vendendo" os cuidados de enfermagem como se fossem mercadoria. Se está institucionalizada a propina em hotéis, restaurantes, táxis e outros serviços, onde o cliente é pessoa sadia, capaz de se defender quando se serite lesado, tal não ocorre nos hospitais. Lá o paciente encontra-se indefeso, amedrontado, inseguro e totalmente entregue às mãos de pessoas, que muítas vezes, nem foram escolhidas por ele: Faltando-lhe a saúde e a energia para protestar, temeroso de que um protesto resulte em maus tratos, ele aceita passivamente "comprar" bom atendimento, pois é a vida dele que está em jogo.

Finalmente, incluímos entre os aspectos éticos o problema da atitude e aparência profissional. Antes da enfermeira ter oportunidade de provar sua eficiência e capacidade, ela impressionará pela sua apresentação pessoal e profissional. Daí a importância do aspecto do uniforme, que além de imaculadamente limpo, deverá destacar-se pela elegância e discrição. Algumas enfermeiras, esquecidas deste aspecto profissional, apresentamse ao hospital para trabalhar com uniforme inadequado, isto é, excessivamente curto, ou transparente ou colante, quando não, as três características concomitantemente. fácil deduzir porque a enfermeira assim trajada não consegue impor respeito e nem ter autoridade moral para liderar a sua equipe de trabalho.

\section{CONSIDERAÇOES FINAIS}

A casuística ainda poderia continuar por mais páginas e páginas, porém os exemplos de casos aqui narrados, frutos da observação pessoal ou resultados de entrevistas mantidas com enfermeiras e outros funcionários de hospitais e clínicas particulares, parecem constituir quadro suficiente para uma análise e uma tomada de consciência. Embora a magnitude dos problemas tenha nos impressionado, não houve preocupação em trazer sugestōes para resolvê-los; nem é 
OGUISSO, T. e SCHMIDT, M.J. - Problemas Assistenciais de Enfermagem nos Hospitais e Clínicas Particulares. Rev. Bras. Enf.; DF, 28:24-37, 1976.

objeto deste trabalho. Mas, é a partir do reconhecimento da situação concreta que se torna possível a busca de soluçōes adequadas.

Alguns problemas, talvez, não possam ser solucionados satisfatoriamente, pelo menos no momento, cabendo apenas optar entre aceitar a situação e continuar no emprego, ou protestar e demitir-se. Trata-se de uma solução extremista, embora alguns casos requeiram soluçōes extremas.

Para outros problemas, acreditamos que só o Conselho de Enfermagem poderá ter competência e condiçōes de atuação. São os casos de enfermeiras que emprestam ou dão os nomes para hospitais, sem neles prestar qualquer serviço.

Mas, muitos dos problemas levantados dependem mesmo é de melhor preparo e atualização permanente das enfermeiras. Falta de habilidades e destrezas manuais e atitude não condizente com os padrōes profissionais desejáveis foram os pontos mais fracos, observados nas enfermeiras, especialmente as formadas mais recentemente.

Com melhor preparo, a enfemeira poderá fazer mais treinamento e exercer maior supervisão do pessoal, de forma sistemática e permanente, revertendo em solução eficiente para um grande número de problemas analisados.

A rede de assistência médica e hospitalar está se ampliando rapidamente nas grandes capitais, mais por iniciativa de particulares do que do Estado.

Os hospitais governamentais, em geral, dependem de concurso para admissão de enfermeiras. Mesmo que não houvesse esta exigencia, a tendência para o futuro é a abertura de campo de trabalho nos hospitais ou clínicas particulares. Pois, à medida que o país vai atingindo estrágios mais avançados de desenvolvimento, as áreas de assistência à saúde e educação vão sendo delegados progressivamente para iniciativas particulares.

E mister, portanto, que as escolas de enfermagem também voltem sua atenção para os hospitais particulares, utilizando-os como campos de estágio de algumas especialidades. Assim. as alunas teriam oportunidade de lidar com pacientes mais diferenciados e com acompanhantes. Estes ainda não são bem aceitos pelas enfermeiras, em geral, sob alegação de que "atrapalham o serviço". E, contixdo, um dos aspectos de humanização pouco considera.do em hospitais governamentais, mas que faz parte integrante da dinâmica de hospital particular. Para o paciente é motivo de apoio e segurança a presença de acompanhante. Só esta razão já deveria bastar para a enfermeira aceitar bem a figura do acompanhante. Por outro lado, a presença de alunas contribuiria também para melhorar o atendimento ao paciente, pois todo o pessoal de enfermagem sabendose observado e avaliado por elas, procuraria caprichar na execução das técnicas.

Além disso, o estágio em hospitais particulares fará com que se abram as perspectivas de trabalho para as futuras enfermeiras. De um lado, os hospitais que tenham recebido alunas passarão a conhecer melhor as possibilidades e funçōes das enfermeiras. Também os pacientes aos poucos irão distinguindo a enfermeira de outros profissionais da enfermagem. Com isto, acreditamos que esses hospitais passem a adotar atitude favorável com relação à contratação de enfermeiras. $E$ estas, é sabido, tendem a preferir trabalhar em hospitais onde já estagiaram como alunas, pois a adaptação é facilitada pelo conhecimento anterior da planta física, do pessoal, da distribuição de unidades e serviços.

Por isto tudo, é necessário que professoras de enfermagem e alunas defrontem com a realidade dos hospitais particulares, com seus problemas éticos 
OGUISSO, T. e BCFMIDT, M.J. - Problemas Assistenciais de Enfermagem nos Hospitals e Clínicas Particulares. Rev. Bras. Enf;; DF, $28: 24-37,1976$.

e técnicos. Sentindo os problemas, enfrentando-os ou decidindo a respeito, principalmente, dos problemas éticos, estará a docente de enfermagem atuando na formação da atitude profissional. Só assim será possível integrar, realmente, a ética no exercício profissional, deixando ela de ser uma matéria teórica, restrita à sala de aula e ao idealismo da professora da disciplina, e sem aplicabilidade alguma no trabalho do dia a dia.

Urge pois, que cada uma de nós, enfermeiras militantes nos hospitais, no ensino ou em outras áreas, assuma a parcela de responsabllidade que nos cabe, procurando e levantando com coragem e humildade os problemas e falhas existentes. E, daí, passar a enfrentá-los com tirocínio, decisão e energia.

\section{REFERENCIAS BIBLIOGRAFICAS}

1. CaRdehal, L. Dicionário Terminológico de Ciências Médicas, Salvat Ed., s id.

2. CARVALHO, A.C. - Considerações sobre o ensino de campo na enfermagem. Rev. Bras. Enf., Rio, 25 (5) : 149-153, out./dez. de 1972.

3. ENGEL, V. - Situaçāo da Enfermagem nos Hospitais de Santa Catarina, Rev. Bras. Enf., Rio, 17 (1 e 2): 36-41, fev./abril de 1964.

4. FELDMAN, M.A. et al - Aspectos de humanizaçåo do Serviço de Enfermagem no Hospital do Servidor Público Estadual de Sāo Paulo, Rev. Bras. Enf., Rio, 26 (6) : 515526, out./dez. de 1973.

5. FORTES, P. - Dicionário Médico, Ed. Guanabara.

6. GODOY, I.L. \& SOUZA, M.L.D. O papel da Enfermeira nos serviços de saúde no Estado do Río de Janeiro, Rev. Bras. Ent., Rio, 24 (5) : 142-150, Jul./set. de 1971.

7. LAMBERTSEN, E.C. - Equipe de Enfermagem, ABEn, 1966.
8. MOURA, D. - Visita aOs maus hospitais, in JORNAL DA TARDE, SaO Paulo, pgs. 16 e 28, ediç̧̃o de 14-4-75.

9. MOURA, D. - Perigo: hospitais, in JORNAL DA TARDE, Săo Paulo, pg. 16, ediçāo de 2-5-75.

10. OGUISsO, T. - Os aspectos legais da anotaçăo de enfermagem noprontuário do paciente, tese de docência livre apresentada à Escola de Enfermagem Ana Neri, da UFRJ, 1974.

11. MEZZOMO, A.A. - Unidade de Emergência num hospital de 200 leitos, Revista Paulista de Hospitais, Sảo Paulo, 26 (1): 38-44, jan. de 1969.

12. PICANÇO, I. et al - Uma tentativa de avaliaçáo dos serviços de enfermagem de hospitais contratados pelo INPS em Sāo Paulo, Rev. Bras. Enf., Rio, 25 (4) : 193214, jul./set. de 1972. 